\title{
Hypoglycemic and Hypolipidemic Effect of Bitter Kola (Garcinia kola) Seed Extract on Alloxan-Induced Diabetic Albino Rats
}

\author{
Ibanga I. Etim1, Nkereuwem S. Etukudoh², Olaniru B. Olumide3, Obeta M. Uchejeso1*, \\ Nwapi L. Lucy'1, Fiyaktu Y. Bwotle ${ }^{3}$
}

\author{
${ }^{1}$ Department of Chemical Pathology, Federal School of Medical Laboratory Science, Jos, Nigeria \\ ${ }^{2}$ Department of Haematology, Federal School of Medical Laboratory Science, Jos, Nigeria \\ ${ }^{3}$ Department of Chemical Pathology, Jos University Teaching Hospital, Jos, Nigeria \\ Email: *uchejesoobeta@gmail.com
}

How to cite this paper: Etim, I.I., Etukudoh, N.S., Olumide, O.B., Uchejeso, O.M., Lucy, N.L. and Bwotle, F.Y. (2020) Hypoglycemic and Hypolipidemic Effect of Bitter Kola (Garcinia kola) Seed Extract on Alloxan-Induced Diabetic Albino Rats. Journal of Biosciences and Medicines, 8, 127-134. https://doi.org/10.4236/jbm.2020.86012

Received: May 4, 2020

Accepted: June 7, 2020

Published: June 10, 2020

Copyright $\odot 2020$ by author(s) and Scientific Research Publishing Inc. This work is licensed under the Creative Commons Attribution International License (CC BY 4.0).

http://creativecommons.org/licenses/by/4.0/

(c) (i) Open Access

\begin{abstract}
The treatment and management of diabetes mellitus has been a challenge to achieve a total cure using conventional drugs. Hypoglycemic and hypolipidemic effects of bitter kola (Garcinia kola) seed extract on alloxan-induced diabetic rats were studied as a local product. Albino rats weighing about $200 \mathrm{~g}$ were investigated in groups using $200-800 \mathrm{mg} / \mathrm{kg}$ weight of bitter kola seed extract and the sample examined for glucose and lipid profiles using enzymatic methods and statistically analyzed using statistical package for social science (SPSS) windows, version 20.0. The results were expressed as the Mean $\pm \mathrm{SD}$. The results for the serum glucose and low density lipoprotein cholesterols (LDL-C) concentrations of untreated diabetic rats, and treated rats showed a significant $(\mathrm{P}<0.05)$ progressive decrease from $200-800 \mathrm{mg} / \mathrm{kg}$ when compared to the control rats. Total cholesterol (TC) and triglycerides (TG) concentrations for untreated diabetic rats, and treated rats showed increase in concentration which was not significant $(\mathrm{P}>0.05)$ from $200-800 \mathrm{mg} / \mathrm{kg}$ weight when compared with the controls. High density lipoproteins (HDL-C) concentrations for untreated diabetic rats, and treated rats showed increase in concentration which was significant $(\mathrm{P}<0.05)$ from $200-800 \mathrm{mg} / \mathrm{kg}$ weight when compared with the controls. This study confirms the hypoglycemic and hypolipidemic effects of bitter kola (Garcinia kola) seed extract.
\end{abstract}

\section{Keywords}

Hypoglycemia, Hypolipidemia, Bitter Kola, Diabetic Mellitus 


\section{Introduction}

Diabetes mellitus is the commonest endocrine disorder known to man. It is estimated that there are 135 million people in the world with diabetes and that this figure would rise to 380 million by 2025 [1]. This WHO report also pointed out that low and middle income countries will bear the brunt of the increase with Africa contributing significantly to this rise [2]. Diabetes primary defect is in fuel metabolism and this culminates in widespread multi-organ complications that ultimately affect every system of the body including the hematopoietic system. Diabetes is associated with profound alterations in plasma lipid and lipoprotein profile and with an increased risk of coronary heart disease [3]. Increased triglyceride and reduced high density lipoprotein cholesterol levels are the key characteristics of dyslipidemia in type 2 diabetes. The increasing incident of Diabetes mellitus in the developing countries especially in the younger age group affecting mainly the people in the productive years of their lives is also of great concern [4]. The chronic hyperglycemic of diabetes is associated with long term damage, dysfunction and failure of different organs especially the eyes, kidney, nerves, heart and blood vessels [5].

The laboratory determination of blood products and parameters for the purpose of disease diagnosis is highly accurate, sensitive and reliable and has remained the bedrock of ethical and rational research, disease diagnosis, prevention and treatment [6]. Reactive Oxygen Species (ROS) have been implicated in the mechanism of damage of red blood cells in diabetic patients [7]. As a consequence, complications develop which consist of mainly abnormalities in function, morphology and metabolism of erythrocyte, leucocytes and platelets [8]. It is an established fact that $\mathrm{RBC}$ and $\mathrm{WBC}$ decrease in diabetic than non-diabetic patients [9]. Anaemia has also been identified succinctly as a common complication of diabetes mellitus [10]. Lipid measurements are integral components of risk prediction in the primary prevention of cardiovascular disease and management of therapy in the primary and secondary prevention of coronary heart disease [11].

This article could be justified due to the fact that conventional treatment of diabetes mellitus is based on oral hypoglycemic agents and use of insulin. Unfortunately, these agents do not restore normal glycemic state and even fail after some time. These are outside the numerous complications of side effects they present on prolonged usage. The need to discover an oral hypoglycemic agent that will not only restore normal glycemia but also ameliorate the gamut of complications associated with diabetes becomes apparent and thus, this study seeks to determine the effect of oral administrations of bitter kola seed extract on hyperglycemic and hyperlipidemic induced diabetic rats and also seek to determine the oral hypoglycemic agent as alternative to conventional drugs. In addition, lipids and lipoproteins are virtually involved in the development of atherosclerosis, a pathogenic process that is the underlying cause of the common cardiovascular disorders of myocardial infarction, cerebrovascular disease and 
peripheral vascular disease [12].

The main characteristic of type-1 diabetes mellitus is an autoimmune destruction of the pancreatic beta cells, leading to lack of insulin production. In animal models, this deficiency in insulin production is achieved by a variety of different mechanisms, ranging from chemical ablation of the beta cells to breeding rodents that spontaneously develop autoimmune diabetes [13]. In chemically induced model of type- 1 diabetes mellitus, a high percentage of the endogenous beta cells are destroyed, and thus, there is little endogenous insulin production, leading to hyperglycemia and weight loss. Chemically induced diabetes not only provides a simple and relatively cheap model of diabetes in rodents but can also be used in higher animals [3]. Alloxan is used to induce diabetes because of its similarity in structure to glucose. Glucose can compete with alloxan and thus, fasting animals tend to be more susceptible [14]. One disadvantage with chemically induced diabetes is that, the chemical can be toxic at other organs of the body. It should also be noted that changes in P450 isoenzymes in the liver, kidney, lung, intestine, testes and brain have been reported after administration of alloxan, and thus, this should be considered when drugs are being tested in these model [15].

Garcinia kola, commercially known as Bitter Kola belongs to the family Clusiacea or Guttiferae. The plant grows from the seed cultivation and or with cuttings to a medium size and up to about $12 \mathrm{~m}$ in height. It grows more easily by the cutting method. The Bitter Kola seed is smooth and elliptically shaped, with yellow pulp and brown seed coat. Biter kola is highly valued in African ethnic medicine because of its varied and numerous uses which are social and medicinal, thus making it an essential ingredient in folk medicine. Medicinal plants such as Bitter kola are believed to be an important source of flavonoids and chemical substances with potential therapeutic benefits [16].

The medicinal importance of bitter kola is based mainly on the photochemical components of the plants [17]. Some of these components isolated include: oleoresin, tannin, saponins, and alkaloids. Other components isolated from bitter kola seeds are bioflavonoid such as kola flavanone, and hydroxyflavonoids. These are the chromanoids, the garcioc and garcinal, together with tocotrienol [18]. There are also other constituents namely, 1, 3, 8, 11-benzophenones and Garcinia biflavanones (GB-1 GB2) and kola flavonone [9].

The aim of the study is to determine the hypoglycemic and hypolipidemic effects of bitter kola (Garcinia kola) seed extract on alloxan-induced diabetic rats.

\section{Materials and Methods}

\subsection{Laboratory Animals}

Eighty male 10 - 12 weeks old albino wistar rats weighing about $200 \mathrm{~g}$ were purchased from Animals Friend Pet Shop at No.92 Royce Road, Owerri, Imo State. Nigeria. The animals were kept in cages to acclimatize at an ambient temperature of $26^{\circ} \mathrm{C}-28^{\circ} \mathrm{C}$ and adequate ventilation was given for two weeks and fed 
with standard growers mash from vital feeds Nigeria Ltd. And clean water ad libitum. They were handled in accordance with National Institute of Health (NIH) guidelines for the care and use of laboratory animals [19].

\subsection{Preparation of Aqueous Extract of Bitter Kola}

Fresh Bitter Kola (Garcinia kola) seeds (6 kg) were purchased from Ekeonunwa market, Douglas road, Owerri, Imo State, Nigeria. The extraction method used was the modified method of Parekhi et al. [20] and Sofowora [21]. In this process, the outer testa of each Garcinia kola seed was removed washed and air dried for about $24 \mathrm{hrs}$ at $30^{\circ} \mathrm{C}$ room temperature. Each seed was cut into small pellets with kitchen knife and the resulting pellets were subsequently dried in an electric oven for $12 \mathrm{hrs}$ at $4^{\circ} \mathrm{C}$. The dried seed pellets were ground to fine powder using electric blender and sieved with 10 um sieve. $100 \mathrm{~g}$ of the powder was soaked in $150 \mathrm{ml}$ of distilled water for three days in a clean and sterilized $200 \mathrm{ml}$ conical flask. The flask was shaken vigorously intermittently, and then left to stand at room temperature for 72 hours. The resultant mixture was then filtered with Whiteman's No. 1 filter paper and sterile cotton wool to remove tiny particles. The solution was then dried at $65^{\circ} \mathrm{C}$ using the water bath. The semisolid concentration of the extract was collected in sterile pre-weighed screw-capped bottles and labeled accordingly and refrigerated at $4^{\circ} \mathrm{C}$ to avoid degradation when the extract was not used immediately in line with Parekhi et al. [20]. Ukaoma et al. [22] and other researchers [9] [17] [18] have put phytochemicals of bitter kola, though in this study the bitter kola was grinded in whole and rats were fed with whole extract.

\subsection{Induction of Diabetes Mellitus}

Alloxan was purchased from Qualikems Laboratory Reagents, Saint Louis, USA.

Lot No: A110109, Batch No: 021112.

A single dose of freshly prepared alloxan monohydrate dissolved in $2.5 \mathrm{ml}$ of distilled water was injected intra-peritoneal at a dose of $30 \mathrm{mg} / \mathrm{kg}$ body weight into seventy rats. After $72 \mathrm{hrs}$, a blood sample was collected by tail vein tapping and blood glucose was monitored. Rats that had blood glucose level above 11.1 $\mathrm{mMol} / \mathrm{L}$ were considered diabetic and selected for the study.

\subsection{Experimental Animal Grouping}

Rats that have blood glucose concentration level above $11.1 \mathrm{mMol} / \mathrm{L}$ were selected and divided into five groups of 10 rats each in addition to the control group and treated as follows:

1) Group one consisted of non-diabetic rats (control).

2) Group two consisted of untreated diabetic rats.

3) Group three consisted of diabetic rats treated with $200 \mathrm{mg} / \mathrm{kg}$ weight of bitter kola seed extract.

4) Group four consisted of diabetic rats treated with $400 \mathrm{mg} / \mathrm{kg}$ weight of bit- 
ter kola seed extract.

5) Group five consisted of diabetic rats treated with $600 \mathrm{mg} / \mathrm{kg}$ weight of bitter kola seed extract.

6) Group six consisted of diabetic rats treated with $800 \mathrm{mg} / \mathrm{kg}$ weight of bitter kola seed extract.

\subsection{Sample Collection}

After the administration of the last dose of the bitter kola (Garcinia kola) seed extract, rats were fasted overnight and anaesthetized with chloroform and sacrificed. Whole blood was collected by cardiac puncture into plain centrifuge tubes and was allowed to clot and then centrifuged at $3000 \mathrm{rpm}$ for 5 minutes to obtain the serum that was used for the estimation of glucose and lipid profile.

\subsection{Sample Estimation}

Estimation of glucose and lipid profile were in line with Ochei and Kolhatkar [23] methods using Randox diagnostic kits.

\subsection{Statistical Analysis}

Statistical analysis was performed on statistical package for social science (SPSS) windows, version 20.0 test of significance was determined using the student " $t$ " test and the statistical significance was set at $\mathrm{P}<0.05$. The results were expressed as the Mean $\pm \mathrm{SD}$.

\section{Results}

In Table 1, there was progressive decrease in the glucose concentration with increase concentration of the bitter kola seed extract compared to the controls and the untreated diabetic rats respectively.

Total cholesterol concentration obtained does not show much variation irrespective of the different dosages of the bitter kola seed extract administered to the rats but there is a decrease in values of the treated diabetic rats and the controls and the untreated diabetic rats respectively.

Table 1. Groups of rats and concentrations of serum glucose, TC, TG, HDL-C, AND LDL-C.

\begin{tabular}{|c|c|c|c|c|c|}
\hline \multirow{2}{*}{ Groups of Rats } & \multicolumn{5}{|c|}{ Parameters (mMol/L) } \\
\hline & Glucose & $\mathrm{TC}$ & TG & HDL-C & LDL-C \\
\hline Controls & $6.22 \pm 0.21$ & $4.62 \pm 3.12$ & $1.03 \pm 0.03$ & $2.41 \pm 0.36$ & $1.20 \pm 0.42$ \\
\hline Untreated Diabetic Rats & $16.28 \pm 1.34$ & $7.54 \pm 2.34$ & $4.22 \pm 1.07$ & $1.43 \pm 1.31$ & $2.71 \pm 2.04$ \\
\hline $200 \mathrm{mg} / \mathrm{kg}$ body weight of rats & $10.67 \pm 2.01$ & $5.81 \pm 1.42$ & $3.81 \pm 0.43$ & $1.73 \pm 0.02$ & $2.03 \pm 1.13$ \\
\hline $600 \mathrm{mg} / \mathrm{kg}$ body weight of rats & $6.33 \pm 1.12$ & $5.67 \pm 2.22$ & $1.63 \pm 0.24$ & $1.85 \pm 1.11$ & $1.42 \pm 1.05$ \\
\hline $800 \mathrm{mg} / \mathrm{kg}$ body weight of rats & $5.33 \pm 2.13$ & $5.65 \pm 0.42$ & $1.44 \pm 1.26$ & $1.87 \pm 0.32$ & $1.05 \pm 0.31$ \\
\hline
\end{tabular}

TC-Total cholesterol, TG-Triglyceride, HDL-C_High density lipoprotein cholesterol, LDL-C_Low density lipoprotein cholesterol. 
There is a decrease in values of triglyceride in the treated diabetic rats compared to the untreated diabetic rats and the controls.

Progressive increase in the values of HDL-C with increase in concentration of the extract and this demonstrates the anti-oxidative and anti-inflammatory activities of bitter kola seed extract.

Results show a progressive decrease in concentration of LDL-C with increase concentration of the extract compared to the control.

\section{Discussion}

The serum glucose concentration of treated diabetic rats was significantly reduced $(\mathrm{P}>0.05)$ compared to the serum glucose concentration of untreated diabetic rats and that of the controls. This observation is in consistent with the finding of [24]. The reduced serum glucose concentration could be attributed to the anti-diabetic and anti-hyperlipidemic activities of the bitter kola seed extract and this was also pointed out by [25]. The reduced glucose concentration was due to the activity of bitter kola seed extract against inflammation and reactive oxygen species (ROS) of free radical on the pancreatic beta cells.

The total cholesterol concentration of the treated diabetic rats did not show significant increase $(P<0.05)$ but the values were significantly increased $(P<$ $0.05)$ compared to the controls. Also, the TC concentration of the untreated diabetic rats was significantly increased $(\mathrm{P}<0.05)$ compared to the treated diabetic rats.

There was significant increase $(\mathrm{P}<0.05)$ in the HDL-C concentrations of the controls compared to the treated diabetic rats. The HDL-C has the ability to promote cholesterol efflux from cells, have reduced antioxidative and vasorelaxant properties as reported by [26].

However, there was increase in TG concentration of the untreated diabetic rats compared to the treated diabetic rats. This increase is as a result of decrease adipose tissue and muscle lipoprotein lipase activity in the liver and higher VLDLC-C production by the liver and their decreased clearance.

There was a marked decrease in the LDL-C concentration of the treated diabetic rats compared to the untreated diabetic rats. The decrease in LDL-C and increase in HDL-C demonstrates the effectiveness of the bitter kola seed extract against inflammation and reactive oxygen species (ROS) of the free radicals.

\section{Conclusions}

There is significant decrease in glucose concentration and low density lipoprotein; and a non-significant increase in total cholesterol and triglycerides and significant decrease in high density lipoproteins. This study confirmed the hypoglycemic and hypolipidemic activities of bitter kola seed extract and its potency to protect the pancreatic beta cells against inflammation and reactive oxygen species (ROS) of free radicals.

In search for non-conventional oral hypoglycemic and hypolipidemic agent 
that will not only restore normal glycemic but also ameliorate the gamut of complication associated with the conventional drugs, the bitter kola (Garcinia kola) seed extract should be an alternative.

It is therefore, recommendable that further studies are required to substantiate the pharmacodynamics pathway by which bitter kola seed extract affects diabetes using pancreatic beta cells.

\section{Acknowledgements}

The authors acknowledge Professor Nwosu DC of Imo State University, Owerri-Nigeria for his mentoring efforts during this research work. Also AMLSN Rock City, 2018 is also acknowledged as the paper was presented during the scientific conference that held September, 2-4 2018.

\section{Conflicts of Interest}

The authors declare no conflicts of interest regarding the publication of this paper.

\section{References}

[1] World Health Organization (WHO) (2012) Global Databases, July, 2012.

[2] King, H., Aubert, R.E. and Herman, W.H. (1998) Prevalence, Numerical Estimates, Projection and Diabetes Care. In: Global Burden of Diabetes, Medical Pub., Geneva, 634.

[3] Farombi, E.O., Shrotriya, S.S. and Surh, Y. (2009) Effect of Kolaviron on Dimethyl Nitrosamine-Induced Liver Injury. International Journal of Environment and Public Health, 20, 423-442.

[4] Aldrich, J.E. (2003) Clinical Enzymology. In: Anderson, S.C. and Cockayne, S., Eds., Clinical Chemistry Concepts and Applications, McGraw Hill, New York, 261-284.

[5] Anthony, C. (2005) LDL-Cholesterol: "Bad" Cholesterol or "Bad" Science? Journal of American Physicians and Surgeons, 10, 83-89.

[6] Adeneye, A.A. and Agbaje, E.D. (2008) Pharmacological Evaluation of Oral Hypoglycemic and Antidiabetic Effects of Fresh Leaves Ethanol Extract of Morinda Lucida Benth, in Normal and Alloxan Induced Diabetic Rats. African Journal of Biomedical Research, 11, 65-71. https://doi.org/10.4314/ajbr.v11i1.50668

[7] Adaramoye, O.A., Nwaneri, V.C., Anyanwu, K.C. and Farombi, E.O. (2005) Possible Antiatherogenic Effect of Kolaviron in Hypercholesterolemia Rats. Journal of Pharmacology and Physiology, 32, 40-46. https://doi.org/10.1111/j.1440-1681.2005.04146.x

[8] Weiner, D. and Samak, M. (2004) Managing Dyslipidemia in Chronic Kidney Disease. Journal of General Internal Medicine, 19, 1045-1050. https://doi.org/10.1111/j.1525-1497.2004.40049.x

[9] Cotter Hill, P.J., Scheinmann, F. and Stenhouse, T.A. (2008) Extractives from Guttiferae: Kola Flavonone, a New Biflavonone from the Nuts of Garcinia kola Heckel. Journal of Chemical Society, Perkin, 4, 241-246.

[10] Lowry, O.H., Rosebrough, N.J., Farr, A.L. and Randall, R.J. (2003) Protein Measurement with the Folin Phenol Reagent. Journal of Biological Chemistry, 193, 265-275.

[11] Reitman, S. and Frankel, S.A. (2006) Colorimetric Method for the Determination of 
Serum Lipids. American Journal of Clinical Pathology, 28, 56-63. https://doi.org/10.1093/ajcp/28.1.56

[12] Carl, A., Edward, R. and David, E. (2008) Lipids and Lipoprotein. In: Fundamental of Clinical Chemistry, 6th Edition, Elsevier, Amsterdam, 428.

[13] Ibrahim, S., Mustafa, K., Samir, A. and Amal, M. (2007) Epidemiology of Diabetes Mellitus in Relation to Other Cardiovascular Risk Factor in Lebanon. Eastern Mediterranean Health Journal, 3, 462-466.

[14] Alison, M., Michael, P. and Penny, K. (2008) Nutritional Management of Lipid for Overweight and Obesity. Journal of Nutritional Medicines, 3, 573-584. https://doi.org/10.2217/17460875.3.5.573

[15] Vaziri, N.D. (2003) Molecular Mechanism of Disorder in Nephrotic Syndrome. Kidney International, 63, 1064-1965. https://doi.org/10.1046/j.1523-1755.2003.00941.x

[16] Iwu, M.M. (1993) Garcinia kola Seed. In: Handbook of African Medical Plants, CRC Press, Boca Raton, 520.

[17] Iwu, M.M., Igboko, O.A., Okunji, C.O. and Tempesta, M.S. (1990) Anti-Diabetic and Aldose Reductase Activities of Biflavanones of Garcinia kola. Journal of Pharmacology, 42, 290-292. https://doi.org/10.1111/j.2042-7158.1990.tb05412.x

[18] Iwu, M.M., Igboko, O.A., Onwuchekwa, U. and Okunji, C.O. (2005) Evaluation of the Bioflavonoid of Garcinia kola Seeds. Journal of Ethno Pharmacology, 21, 127-138. https://doi.org/10.1016/0378-8741(87)90123-1

[19] National Institutes of Health (NIH) (1985) Author Guide for the Care and Use of Laboratory Animals. NIH Publication, Ellicott, Number 85.

[20] Parekhi, J., Jadeja, D. and Chanda, S. (2005) Efficiency of Aqueous and Methanolic Extract of Some Medical Plants for Potential Antibiotic Activities. Turkey Journal of Biology, 25, 203-210.

[21] Sofora, A.E. (1991) Pharmacological Evaluation of African Plants. West Africa Journal of Pharmacology, 19, 51-54.

[22] Ukaoma, A.A., Ukaoma, V.O., Okechukwu, R.I. and Iwuagwu, M. (2013) Phytochemical Screening and Antibacterial Properties of Garcinia kola. The Journal of Phytopharmacology, 2, 34-38. http://www.phytopharmajournal.com

[23] Ochei, J. and Kolhatkar, A. (2000) Lipids and Lipoprotein. In: Medical Laboratory Science: Theory and Practice, McGraw Hill Publishing Co. Ltd., New Delhi, 311-347.

[24] Ghacha, R., Sinha, A.K. and Karkar, A.M. (2001) Serum Fructosamine as Marker of Chronic Glycemic State in Type 2 Diabetic Hemodialysis Patients. In: Dialysis and Transplant, EandS Publication Ltd., New York, 724.

[25] Hayden, M.R. and Tyagi, S.C. (2002) Intimal Redox Stress: Accelerated Atherosclerosis in Metabolic Syndrome and Type 2 Diabetes Mellitus. Journal of Atheroscleropathy, Cardiovasculogy and Diabetology, 1, 3-8. https://doi.org/10.1186/1475-2840-1-3

[26] Wiernsperger, N.F. (2003) Oxidative Stress as a Therapeutic Target in Diabetes. In: Diabetes Metabolism, Elsevier Churchill, Philadelphia, 3rd Edition, 563. 